\title{
Spatial Heterogeneity of Soil Moisture and the Scale Variability of Its Influencing Factors: A Case Study in the Loess Plateau of China
}

\author{
Qiang Feng ${ }^{1,2}$, Wenwu Zhao ${ }^{1, *}$, Yang Qiu ${ }^{3}$, Mingyue Zhao ${ }^{1}$ and Lina Zhong ${ }^{1}$
}

1 State Key Laboratory of Earth Surface Processes and Resource Ecology, College of Resources

Science and Technology, Beijing Normal University, Beijing 100875, China;

E-Mails: fengqiang921@163.com (Q.F.); zmy@mail.bnu.edu.cn (M.Z.);

zhong_lina@163.com (L.Z.)

2 College of Forestry, Shanxi Agricultural University, Taigu, Shanxi 030801, China

3 School of Geography, Beijing Normal University, Beijing 100875, China;

E-Mail: qiuyang69@bnu.edu.cn

* Author to whom correspondence should be addressed; E-Mail: zhaoww@bnu.edu.cn;

Tel.: +86-10-5880-2125; Fax: +86-10-5880-2125.

Received: 20 May 2013; in revised form: 20 July 2013 / Accepted: 2 August 2013 /

Published: 16 August 2013

\begin{abstract}
Soil moisture is an important factor for vegetation restoration and ecosystem sustainability in the Loess Plateau of China. The strong spatial heterogeneity of soil moisture is controlled by many environmental factors, including topography and land use. Moreover, the spatial patterns and soil hydrological processes depend on the scale of the site being investigated, which creates a challenge for soil moisture forecasts. This study was conducted at two scales: watershed and small watershed. The goal of the study was to investigate the spatial variability in soil moisture and the scale effect of its controlling factors, as well as to provide references for soil moisture forecasting and studies of scale transformation. We took samples at 76 sites in the Ansai watershed and at 34 sites in a typical small watershed within the Ansai watershed in August. Next, we measured the soil moisture in five equal layers from a depth of $0-100 \mathrm{~cm}$ and recorded the land use type, location on the hill slope, slope, aspect, elevation and vegetation cover at the sampling sites. The results indicated that soil moisture was negatively correlated with relative elevation, slope and vegetation cover. As depth increased, the correlations among slope, aspect and soil moisture increased. At the small watershed and watershed scales, the soil
\end{abstract}


moisture was highest in cultivated land, followed by wild grassland and lowest in garden plots, woodland and shrubland. The soil moisture was distributed similarly with respect to the location on the hill slope at both scales: upper slope $<$ middle-upper slope $<$ middle slope $<$ middle-lower slope $<$ lower slope. The deep layer soil moisture value of the slope top was high, being close to the soil moisture in the lower slope. Therefore, wild grassland or low-density woodland should be prioritized for farmland recovery in the Ansai watershed, and the locations on the hill slope, slope and elevation should be combined to configure different mosaic patterns. For example, low-density woodland or wild grassland would be appropriate for sites with low soil moisture content, such as upper slope, high elevation and steep slope sites. A stepwise regression analysis indicated that the dominant factor controlling the spatial variability of soil moisture values varied at different scales. At the small watershed scale, the order of significance for the influence of environmental factors on soil moisture values was as follows: land use type, slope, relative elevation and vegetation cover. The order of significance at the watershed scale was also determined: location on the hill slope, vegetation cover, slope, relative elevation and sine of the aspect. This result indicated that the influence of different environmental factors on soil moisture variability was dependent on the scale. The forecasting capability of regression models for soil moisture decreases from the small watershed scale to the watershed scale. This study could provide a reference for relevant scale transformation studies and offer guidance for water resource management and vegetation restoration approaches on the Loess Plateau.

Keywords: soil moisture; spatial variability; small watershed; watershed; scale effect

\section{Introduction}

As an important research subject in hydrological research, pedology and environmental studies [1], soil moisture is influenced by many environmental factors, such as rainfall, topography [2-4], solar radiation [5], soil texture [6,7] and land use [8,9]. The spatial distribution of soil moisture is complex, and the factors controlling the pattern's formation are controversial, due to the scale dependence of the spatial variability of soil moisture and the increase in soil moisture heterogeneity as scale expansion [5,10,11]. Research into the multi-scale spatial distribution of soil moisture has received increasing attention in recent years. A study by Zhu and Lin [12] described the influence of soil, topography and crop growth on soil moisture variability at four scales in an agriculture landscape. Rosnay et al. [13] developed a scale transfer equation from the local- to kilometer-scale and from the local- to meso-scale using stochastic methods. Numerous studies [14-16] have discussed the application of regional soil moisture data, which are temporally stable, to validate estimated data from remote sensing, thus enabling the development of soil moisture monitoring data at even larger scales.

The Loess Plateau of China is an arid and semi-arid area. This region has one of the most serious water loss and soil erosion problems in China and globally. Water is the key factor in determining the structure and function of ecosystems in this region. The groundwater is buried relatively deeply in the Loess Plateau, and the "soil reservoir", which is composed of soil moisture, is particularly important 
for vegetation growth and ecological restoration in this area. Research regarding the spatial distribution of soil moisture on the Loess Plateau in China has predominantly focused on a single scale, such as a land parcel [17], slope [18-20] or small watershed [21,22]. There is little cross-scale research, and there are few discussions about the scale of sampling and sample spacing [23,24].

The soil texture of the Loess Plateau has two characteristics: the homogeneity of particle compositions and the zoning of their distribution. According to the zoning map of soil texture on the Loess Plateau, the study area (Ansai watershed) is located in the light loam zone, where soil texture tends to be homogeneous [25]. At the watershed scale, there is no clear variation in the climatic conditions [22].

Many relevant studies focus on a single scale, but there is little cross-scale research on the Loess Plateau in China. The findings derived from research at a single scale offer weak support in ecological construction activities. The Loess Plateau of China suffers some of the most severe water loss and soil erosion problems in the world. The Loess Plateau is significant in both theory and practice, because it allows multi-scale studies of the spatial heterogeneity of soil moisture, thus providing references for scale transformation studies and for proposing vegetation restoration approaches. It is generally accepted that topography is an important factor that controls soil moisture under wet conditions, and the soil property (soil texture) is the main factor influencing the soil moisture distribution under drought conditions [26]. The soil moisture was measured in August, which is in the wet season. Due to the homogeneity of the soil texture in Ansai and the lack of multi-scale studies of soil moisture in the Loess Plateau region of China, we chose to study the spatial distribution of soil moisture and its influencing factors on the two scales of small watershed and watershed. The factors that influence soil moisture included environmental factors, such as land use, aspect, location on the hill slope, elevation and vegetation cover; soil texture was not taken into account. Our objective was to reveal the spatial variability in soil moisture and the scale effect of its controlling factors and to provide a reference for relevant scale transformation studies and a basis for water resource management and vegetation restoration on the Loess Plateau.

\section{Materials and Methods}

\subsection{Study Area}

The Yanhe watershed lies in the middle of the Loess Plateau in the northern Shaanxi Province. The subwatershed in this study is located in the upstream section of the Yanhe and is controlled by a hydrometric station called "Ansai" $\left(109^{\circ} 19^{\prime} \mathrm{E}, 36^{\circ} 52^{\prime} \mathrm{N}\right)$; as a matter of convenience, it is referred to as the Ansai watershed. The study area included the Ansai watershed $\left(108^{\circ} 47^{\prime}-109^{\circ} 25^{\prime} \mathrm{E}\right.$, $\left.36^{\circ} 52^{\prime}-37^{\circ} 19^{\prime} \mathrm{N}\right)$ and the Muyu small watershed $\left(109^{\circ} 14.6^{\prime}-109^{\circ} 15.5^{\prime} \mathrm{E}, 36^{\circ} 58.9^{\prime}-36^{\circ} 59.7^{\prime} \mathrm{N}\right)$ (Figure 1), which have an area of $1334 \mathrm{~km}^{2}$ and $1.3 \mathrm{~km}^{2}$, respectively. The study area has a very rugged topography, with an average slope of $23.9^{\circ}$ : over $90 \%$ of the territory is composed of gullies and ridges, and the landform is a typical loess hilly-gullied landscape with elevations ranging from $1057 \mathrm{~m}$ to $1743 \mathrm{~m}$ above sea level, with an average of $1362 \mathrm{~m}$. The area has a typical semiarid continental climate with an average temperature of $8.8{ }^{\circ} \mathrm{C}$ and an average annual precipitation of $505 \mathrm{~mm}$. Rainfall shows high seasonal variability, with more than $60 \%$ of the annual precipitation occurring between July and September. The Ansai watershed is covered by a thick mantle of loess, an 
erosion-prone, fine silt soil. The percentage contents of different particle fractions are as follows: $>0.25 \mathrm{~mm}(0.3 \%), 0.25-0.05$ (18.7\%), $0.05-0.01$ (59\%), 0.01-0.005 (6.2\%), 0.005-0.001 (6.8\%) and $<0.001(9 \%)$ [25]. The Ansai watershed is located on a warm forest steppe, where natural forests have been destroyed. There were a large number of artificial plantings, predominantly Robinia pseudoacacia and Hippophae rhamnoides; the wild slope was covered with an herbaceous plant community that was composed mainly of Artemisia gmelinii, Artemisia giraldii, Lespedeza davurica and Stipa bungeana. There was garden plot planted mainly with apricot and pear trees. The cultivated crops were predominantly maize, millet and broom corn millet; these crops were in the booting stage, growing well at the date of sampling.

Figure 1. Study area and location of the sampling points.

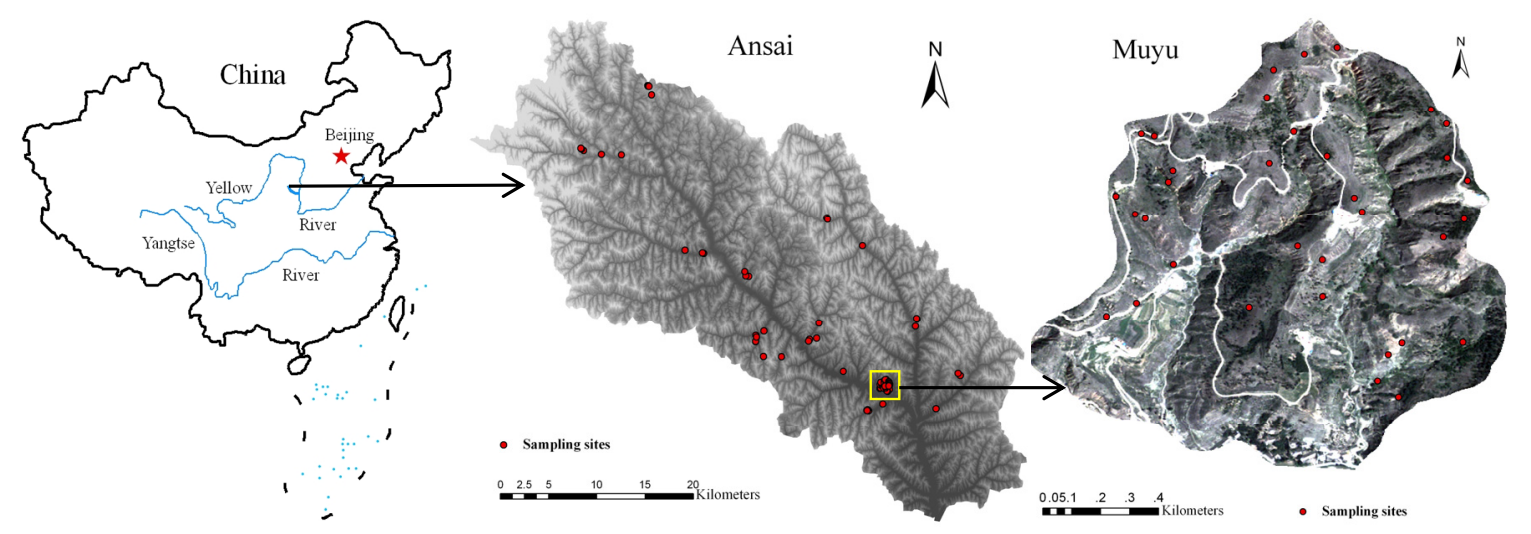

\subsection{Experimental Design and Research Methods}

In August 2012, we selected the Muyu small watershed as typical within the Ansai watershed by combining the current land use, water system, topographic and soil type maps in the study area used to survey the Ansai watershed. We took samples at 34 sites in the small watershed and at 76 sites for the watershed scale. The location of the study area and the distribution of sampling sites are indicated in Figure 1. The number of sampling sites with respect to the land use type and location on the hill slope is shown in Table 1.

The most important consideration for soil moisture research at the watershed scale is to determine how to lessen the effect of individual rainfall events on soil moisture content measurements. This will ensure that the data measured at different study sites are comparable. To further eliminate the influence of rainfall events on soil moisture content measurements, the soil moisture contents were measured 7 days after a rainfall event had occurred. We used a soil auger to drill to depths of $0-20 \mathrm{~cm}$, 20-40 cm, 40-60 cm, 60-80 cm and 80-100 cm. We then measured the soil moisture using the oven-drying method. Three measurement points were collected for each sampling site. The distance between the 3 measurement points was more than $5 \mathrm{~m}$, and the average soil moisture of the 3 points represented the soil moisture of the sampling site. We also used GPS (Trimble GeoExplorer 2008 Series GeoXH) to measure the latitude, longitude and elevation of the sampling sites. The difference between the elevation of the sampling sites and the watershed outlet was used to calculate the relative elevation. True north was 0 degrees, and aspect was the clockwise rotational angle and was measured using a compass. Slope was measured using a slope meter. Three people estimated the 
vegetation cover through observation according to the reference figure. The vegetation cover was calculated as the average of the 3 people's visual measurements. The land use types and locations on the hill slope at the sampling sites were recorded.

Table 1. Number of sampling sites with respect to land use type and location on the hill slope.

\begin{tabular}{cccc}
\hline & & Small watershed scale & Watershed scale \\
\hline Land use type & Shrubland & 4 & 10 \\
& Woodland & 13 & 24 \\
& Garden plot & 1 & 5 \\
& Wild grassland & 13 & 22 \\
& Cultivated land & 3 & 15 \\
\hline Location on the hill slope & Slope top & 2 & 4 \\
& Upper slope & 7 & 19 \\
& Middle-upper slope & 8 & 11 \\
& Middle slope & 7 & 14 \\
& Middle-lower slope & 4 & 12 \\
& Lower slope & 6 & 16 \\
\hline
\end{tabular}

\subsection{Data Analysis}

We completed a Pearson correlation analysis between soil moisture and aspect, relative elevation, slope and vegetation cover. We applied a general linear model (GLM) for a one-way analysis of variance (one-way ANOVA) and a Least-Significant Difference (LSD) method for multiple comparisons to analyze the influence of land use and location on the hill slope on soil moisture. We used the sampling sites as repetitions: the number of sampling sites was the number of repetitions, and thus, false repetition was avoided. All statistical analyses were based on the soil moisture date of the sampling sites, i.e., the average soil moisture of three measurement points at each sampling site.

The stepwise regression analysis selected variables that had a significant influence on the regression equations from among a large number of variables and eliminated the influence of possible multi-collinearity between factors in the interpretation of regression equations. The land use type and location on the hill slope were qualitative environmental factors that were converted into dummy variables for the general stepwise regression analysis. We used a $0-1$ quantization process for the qualitative environmental factors. Shrubland was used as the reference category for land use type, so dummy variables were derived as follows: shrubland $\left(A_{1}=0, A_{2}=0, A_{3}=0, A_{4}=0\right)$, garden plot $\left(A_{1}=1, A_{2}=0, A_{3}=0, A_{4}=0\right)$, woodland $\left(A_{1}=0, A_{2}=1, A_{3}=0, A_{4}=0\right)$, cultivated land $\left(A_{1}=0\right.$, $\left.\mathrm{A}_{2}=0, \mathrm{~A}_{3}=1, \mathrm{~A}_{4}=0\right)$, and wild grassland $\left(\mathrm{A}_{1}=0, \mathrm{~A}_{2}=0, \mathrm{~A}_{3}=0, \mathrm{~A}_{4}=1\right)$. The five land use types required four dummy variables, $\mathrm{A}_{1}-\mathrm{A}_{4}$, which represent "garden plot", "woodland", "cultivated land", and "wild grassland", respectively. The same approach was used for deriving the dummy variables of locations on the hill slope, where the middle-lower slope was used as the reference category. $\mathrm{B}_{1}-\mathrm{B}_{5}$ represent the "upper slope", "lower slope", "slope top", "middle slope", and "middle-upper slope", respectively. With the other quantitative environmental variables, namely, the relative elevation, slope, sine of the aspect (indicating the east-west direction), cosine of the aspect (indicating the 
north-south direction) and vegetation cover, there were a total of 14 independent variables. We applied a stepwise regression analysis to determine the water moisture forecast model at different scales.

\section{Results and Discussion}

\subsection{Relationship between Quantitative Environmental Factors and Soil Moisture Value at Different Scales}

The results of the Pearson correlation analysis between soil moisture values and the quantitative environmental factors, such as aspect, relative elevation, slope and vegetation cover, are listed in Table 2. The correlation coefficient between soil moisture and the cosine of the aspect and the sine of the aspect was not significant. The relative elevation was significantly negatively correlated with soil moisture values, indicating that soil moisture values were higher at sites that were closer to the main stream. This result is in agreement with other research $[4,21,27]$. The correlation between soil moisture values and the relative elevation for all soil layers at the small watershed scale was higher than the correlation at the watershed scale, which indicated that as the scale became larger, the influence of relative elevation on soil moisture values decreased. The slope and soil moisture values in the deep layers were clearly negatively correlated, indicating that a smaller slope was more favorable for soil moisture value infiltration and transfer to deeper layers. A higher vegetation cover resulted in a lower soil moisture value in the deep layers. This trend indicated that the lush vegetation consumed the soil moisture in the deeper layers of the Ansai watershed. The correlation among slope, vegetation cover and the soil moisture value at the surface layer $(0-20 \mathrm{~cm})$ was not significant. This result suggested that the spatial distribution of the surface soil moisture value tended to be more random, due to the dramatic influence of factors, such as evaporation. As depth increased, the correlation among slope, aspect, vegetation cover and soil moisture value increased.

Table 2. Pearson correlation coefficients between quantitative environmental factors and cross-sectional soil moisture value.

\begin{tabular}{ccccccc}
\hline Scale of research & $\begin{array}{c}\text { Depth of soil } \\
\text { layer }\end{array}$ & $\begin{array}{c}\text { Cosine of } \\
\text { aspect }\end{array}$ & $\begin{array}{c}\text { Sine of } \\
\text { aspect }\end{array}$ & $\begin{array}{c}\text { Relative } \\
\text { elevation }\end{array}$ & Slope & $\begin{array}{c}\text { Vegetation } \\
\text { cover }\end{array}$ \\
\hline Small watershed & $0-20 \mathrm{~cm}$ & 0.22 & 0.14 & $-0.53 * *$ & -0.06 & 0.14 \\
scale & $20-40 \mathrm{~cm}$ & 0.27 & 0.16 & $-0.48 * *$ & -0.14 & -0.27 \\
& $40-60 \mathrm{~cm}$ & 0.27 & 0.11 & $-0.62 * *$ & -0.14 & -0.31 \\
& $60-80 \mathrm{~cm}$ & 0.32 & 0.14 & $-0.63 * *$ & -0.29 & $-0.37 *$ \\
& $80-100 \mathrm{~cm}$ & 0.32 & 0.16 & $-0.52 * *$ & $-0.38 *$ & $-0.47 * *$ \\
& Depth-averaged & 0.32 & 0.17 & $-0.64 * *$ & -0.24 & -0.3 \\
\hline Watershedscale & $0-20 \mathrm{~cm}$ & 0.09 & 0.08 & $-0.35 * *$ & -0.04 & 0.02 \\
& $20-40 \mathrm{~cm}$ & 0.19 & -0.01 & $-0.27 *$ & -0.04 & -0.2 \\
& $40-60 \mathrm{~cm}$ & 0.14 & -0.08 & -0.21 & -0.22 & $-0.29 *$ \\
& $60-80 \mathrm{~cm}$ & 0.17 & -0.11 & $-0.25 *$ & $-0.36 * *$ & $-0.38 * *$ \\
& $80-100 \mathrm{~cm}$ & 0.21 & -0.06 & $-0.25 *$ & $-0.37 * *$ & $-0.42 * *$ \\
& Depth-averaged & 0.19 & -0.09 & $-0.33 * *$ & $-0.26 *$ & $-0.31 * *$ \\
\hline
\end{tabular}

Notes: * represents a significant correlation at the 0.05 level; ** represents a significant correlation at the 0.01 level. $n=34$ at the small watershed scale; $n=76$ at the watershed scale. 


\subsection{Relationship between Qualitative Environmental Factors and Soil Moisture Valuesat Different Scales}

\subsubsection{Influence of Land Use on Soil Moisture Value}

As illustrated in Table 3 and Figure 2a, at the smaller watershed scale, the land use type had a significant influence on soil moisture values in the corresponding soil layers, except for $0-20 \mathrm{~cm}$. In general, cultivated land had the highest soil moisture value, followed by wild grassland, with garden plot, woodland and shrubland exhibiting the lowest soil moisture value. The results of multiple comparisons indicated that soil moisture values in the deep layers $(80-100 \mathrm{~cm})$ of wild grassland was higher than that of the shrubland, and both values were lower than cultivated land. Soil moisture values of cultivated land were significantly higher than for the other four land use types. On average, the difference between cultivated land and wild grassland with the second moisture condition was $4.1 \%$, and the difference between cultivated land and shrubland with the lowest soil moisture value content was $7.03 \%$.

Table 3. One-way analysis of variance (ANOVA) for the effects of land use type on soil moisture content.

\begin{tabular}{cccccc}
\hline Scale of research & Source of variation & Depth of Soil layer & d.f. & $\boldsymbol{F}$-ratio & Significance \\
\hline Small watershed & Land use type & $0-20 \mathrm{~cm}$ & 4 & 1.64 & $\mathrm{~ns}$ \\
scale & & $20-40 \mathrm{~cm}$ & 4 & 6.05 & $* *$ \\
& & $40-60 \mathrm{~cm}$ & 4 & 6.16 & $* *$ \\
& & $60-80 \mathrm{~cm}$ & 4 & 12.18 & $* *$ \\
& & $80-100 \mathrm{~cm}$ & 4 & 17.75 & $* *$ \\
Watershed scale & Land use type & Depth-averaged & 4 & 10.85 & $* *$ \\
& & $0-20 \mathrm{~cm}$ & 4 & 0.93 & $\mathrm{~ns}$ \\
& & $20-40 \mathrm{~cm}$ & 4 & 3.15 & $*$ \\
& & $40-60 \mathrm{~cm}$ & 4 & 3.41 & $*$ \\
& & $60-80 \mathrm{~cm}$ & 4 & 5.24 & $* *$ \\
\end{tabular}

Notes: d.f. represents degrees of freedom; $F$-ratio $=\mathrm{MS}$ (treatment)/MS(error); * represents significance at the 0.05 level; ** represents significance at the 0.01 level; ns represents not significant.

As illustrated in Table 3 and Figure 2b, the influence of the land use type on soil moisture values at the watershed scale was similar to the small watershed scale: cultivated land $>$ wild grassland $>$ garden plot $>$ woodland $>$ shrubland. Multiple comparisons indicated that the differences among cultivated land, wild grassland and the garden plot were not significant. The difference between woodland and shrubland was also not significant. For the $20-40 \mathrm{~cm}$ and $40-60 \mathrm{~cm}$ soil layers, the soil moisture value in wild grassland was significantly higher than that of woodland and shrubland. Soil moisture values at 60-80 cm, 80-100 cm and 0-100 cm were significantly higher for wild grassland than shrubland and were not significantly different from woodland. The degree of difference in soil moisture values between individual land use types at the watershed scale was smaller than the difference at the small watershed scale. The difference between cultivated land and wild grassland with the closest soil 
moisture value was only $0.84 \%$, while the difference between cultivated land and wild grassland with the lowest soil moisture value was $2.86 \%$.

Figure 2. Difference in soil moisture value for different land use types.
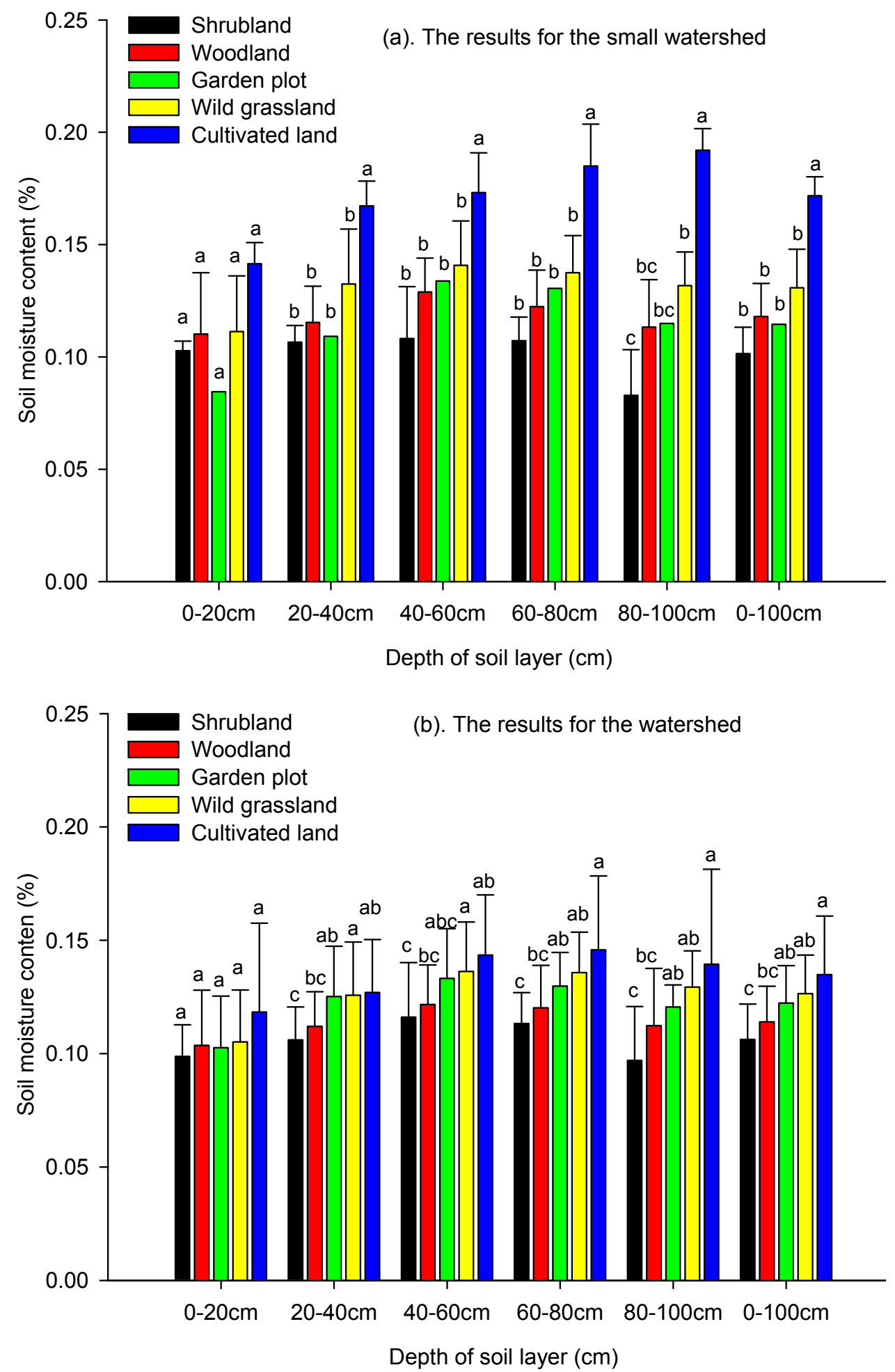

Notes: Different lower-case letters indicate the result of multiple comparisons between different land use types in the same soil layer. As long as two land use types have only one same letter, there is no significant difference between them; if two land use types do not have any same letters, there is significant difference between them. The same is the case for Figure 3. 
Our results for the difference in soil moisture value among the different land use types are similar to those obtained by Huang et al. [22], Liu and Shao [17], Wang et al. [28] and Yao et al. [20]. Despite the greater post-rainfall loss of moisture under grass vegetation than forest and shrub, grass sites exhibit a higher soil moisture content, due to their greater soil retention capacity in the dry period [28]. However, our results differ from those of Wang et al. [29], whose data suggested that soil moisture values of farmland were significantly higher and that soil moisture values of woodland, shrubland and grassland were relatively lower, without a significant difference. This difference in research conclusions is related to the species composition of the woodland and shrubland sites. In this study, woodland and shrubland were both locally dominated by a single species, while the sites in Wang et al. [29] included a comprehensive mix of multiple species.

\subsubsection{Influence of Location on the Hill Slope on Soil Moisture Value}

As illustrated in Table 4 and Figure 3a, the location on the hill slope had a significant influence on soil moisture values in all the soil layers at the small watershed scale. The distribution of average soil moisture at $0-100 \mathrm{~cm}$ for the different locations on the hill slopes (except the slope top) was consecutively ordered: upper slope $<$ middle-upper slope $<$ middle slope $<$ middle-lower slope $<$ lower slope. For the soil layers between 0 and $80 \mathrm{~cm}$, no significant difference was found between soil moisture values of the lower slope and the middle-lower slope. However, soil moisture values of the lower slope and the middle-lower slope were significantly higher than those of the middle-upper slope and the upper slope. In the $80-100 \mathrm{~cm}$ soil layer, soil moisture values of the lower slope were significantly higher than the other locations on the hill slopes, except for the slope top. When depth increased, soil moisture values in the slope top also increased, with a relatively low soil moisture value in the surface layer and an insignificant difference among the slope top, upper slope and middle-upper slope. In the $20-40 \mathrm{~cm}$ soil layer, the difference was not significant between the slope top and the upper slope or between the middle-upper slope and the middle slope. In the 40-60 cm and 60-80 cm soil layers, the differences between the slope top and the four slope positions, other than the lower slope, were not significant. Soil moisture values in the deep layer $(80-100 \mathrm{~cm})$ and the slope top were higher than those in the upper slope, being comparable to soil moisture values in the lower slope. This result is a consequence of the slope top generally being a wide mountain ridge with a terrain that is flat and favorable for moisture infiltration to deep layers.

Surface runoff is mainly generated by two mechanisms: infiltration excess runoff and saturation excess runoff. The soil moisture was different at the different locations on the hill slope, because the runoff generation over infiltration is more common in the hilly-gully region of the loess hills. Farther from the slope top, there is more water from above and greater infiltration. Moreover, the evaporation observed on the upper slope was higher than that observed on the middle and lower slopes, due to, e.g., more direct solar radiation and wind exposure [30]. These results are similar to those of Qiu et al. [21] and He et al. [31], but differ from those of Yao et al. [20], whose study of Yangjuangou at the slope scale suggested that the location on the hill slope had little influence on soil moisture values. This also indicated that it was difficult to apply the research results from one scale to other scales. 
As illustrated in Table 4 and Figure 3b, at the watershed scale, the influence of location on the hill slope on soil moisture values was significant for all soil layers, except the $80-100 \mathrm{~cm}$ layer. The distribution of soil moisture values with respect to the location on the hill slope at the watershed scale was similar to that at the small watershed scale. The average soil moisture value of $0-100 \mathrm{~cm}$, except for the slope top, was consecutively ordered: upper slope $<$ middle-upper slope $<$ middle slope $<$ middle-lower slope < lower slope. In the 0-20 cm, 20-40 cm, 40-60 cm and 60-80 cm soil layers, soil moisture values in the lower and middle-lower slopes were not significantly different, but both were significantly higher than the upper and middle-upper slopes (no significant difference was observed between the upper and middle-upper slopes). The average soil moisture values of $0-100 \mathrm{~cm}$ for the middle, middle-lower and lower slopes were significantly higher than those of the middle-upper and upper slopes. The slope top values were significantly lower than those of the middle-lower and lower slopes. No significant difference in soil moisture values was observed between the slope top and other locations on the hill slope. As depth increased, the relative increasing trend in soil moisture value for the slope top was similar to that in the small watershed. Soil moisture values of the slope top were significantly lower than those of the middle slope at the $0-20 \mathrm{~cm}, 20-40 \mathrm{~cm}$ and $40-60 \mathrm{~cm}$ soil layers. The soil moisture values of the slope top increased to a certain degree, with no significant difference from other locations on the hill slope being observed at depths of 60-80 cm and 80-100 cm, due to the joint action of deep infiltration in the slope top and evaporation. However, the degree of relative change was not as strong as for the small watershed. At the watershed scale, the co-founding effects of other factors, such as slope, aspect, land use and elevation, are more profound to soil moisture than at the small watershed scale. These co-founding factors compromise the variation of soil moisture, resulting in a lower component of location on the hill slope in such variation. Therefore, the relative change detected in the small watershed was much stronger.

Table 4. One-way ANOVA for the effects of location on the hill slope on soil moisture content.

\begin{tabular}{cccccc}
\hline Scale of research & source of variation & Depth of Soil layer & d.f. & F-ratio & Significance \\
\hline Small watershed scale & Location on the & $0-20 \mathrm{~cm}$ & 5 & 9.80 & $* *$ \\
& hill slope & $20-40 \mathrm{~cm}$ & 5 & 9.06 & $* *$ \\
& & $40-60 \mathrm{~cm}$ & 5 & 7.47 & $* *$ \\
& & $60-80 \mathrm{~cm}$ & 5 & 6.13 & $* *$ \\
& & $80-100 \mathrm{~cm}$ & 5 & 4.69 & $* *$ \\
& & Depth-averaged & 5 & 12.11 & $* *$ \\
\hline Watershed scale & Location on the & $0-20 \mathrm{~cm}$ & 5 & 8.72 & $* *$ \\
& hill slope & $20-40 \mathrm{~cm}$ & 5 & 8.11 & $* *$ \\
& & $40-60 \mathrm{~cm}$ & 5 & 6.59 & $* *$ \\
& & $60-80 \mathrm{~cm}$ & 5 & 4.27 & $* *$ \\
& & $80-100 \mathrm{~cm}$ & 5 & 2.21 & $\mathrm{~ns}$ \\
& & Depth-averaged & 5 & 8.66 & $* *$ \\
\hline
\end{tabular}

Notes: d.f. represents degrees of freedom; $F$-ratio $=\mathrm{MS}$ (treatment)/MS(error); ${ }^{*}$ represents significance at the 0.05 level; ** represents significance at the 0.01 level; ns represents not significant. 
Figure 3. Differences in soil moisture value at different locations on the hill slopes.
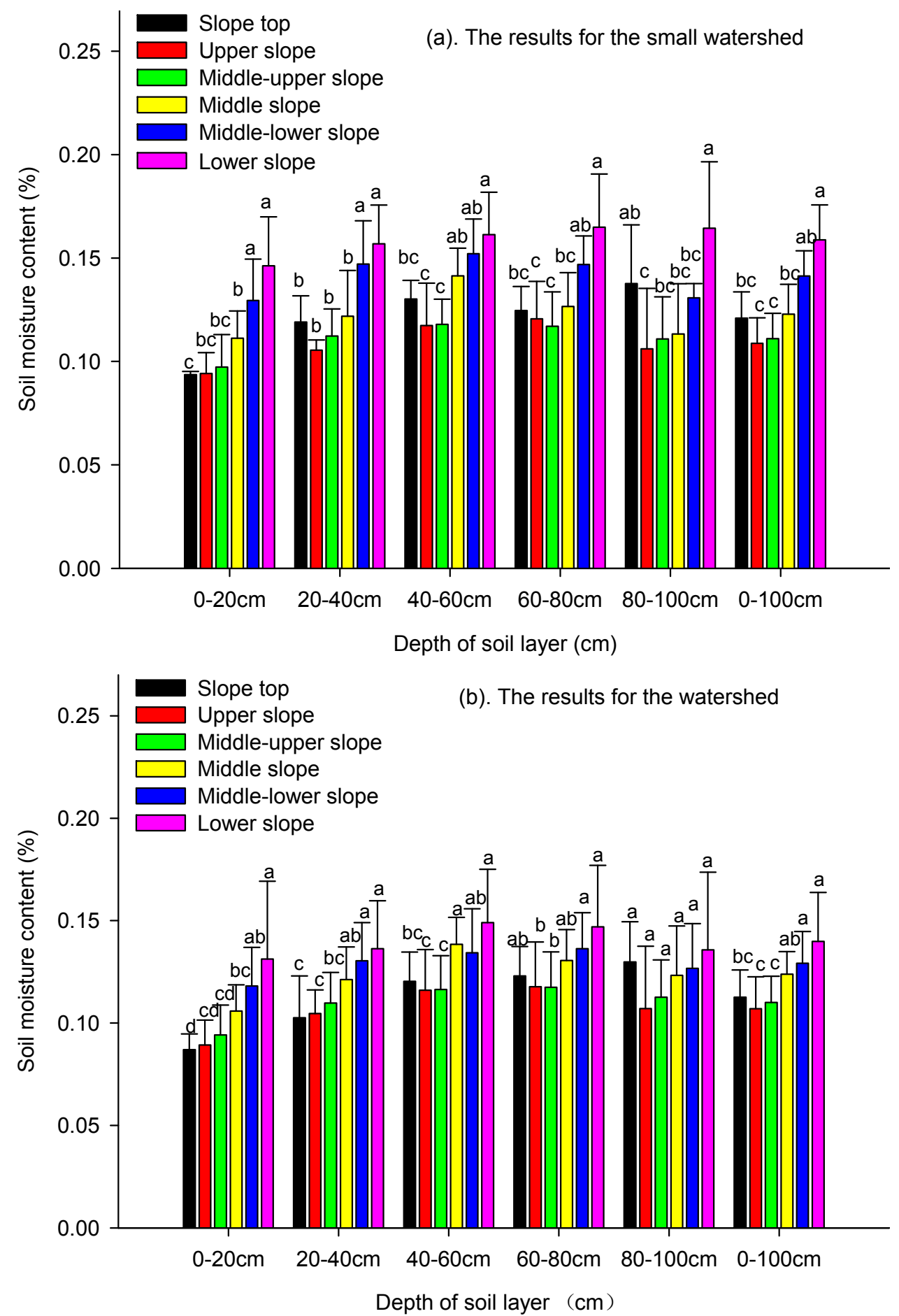

Note: Different lower-case letters indicate the result of multiple comparisons between different locations on the hill slope in the same layer.

\subsection{Statistical Model for Soil Moisture Value Forecasting at Different Scales}

Through the stepwise regression analysis, we screened 14 environmental variables and only introduced independent variables that had a significant influence on the dependent variables in the model. The stepwise regression model for corresponding layers that was derived for the small watershed and watershed scales (Tables 5 and 6) indicated that at these two scales, the location on the 
hill slope was included in the equation for all soil layers from 0 to $60 \mathrm{~cm}$. Vegetation cover was another important factor that influenced soil moisture values and was included in the equation only for the surface layer for the small watershed scale. This variable was also included in the equation for all layers, except the surface layer at the watershed scale, which indicated that vegetation cover was more likely to influence soil moisture values at large scales. The influence of slope on soil moisture values was similar for the two scales and was included in the equation for soil layers below $40 \mathrm{~cm}$. Relative elevation was included in the equation for the $60-80 \mathrm{~cm}$ soil layers at the small watershed scale and the $80-100 \mathrm{~cm}$ soil layers at the watershed scale. The influence of vegetation cover, slope and relative elevation on soil moisture values was similar to the relevant analyses in Table 2. Land use was included in the equation for soil layers below $40 \mathrm{~cm}$ at the small watershed scale and was not included at the watershed scale. In addition, the sine of the aspect was included in the equation for the $20-40 \mathrm{~cm}$ soil layers at the watershed scale, but was not included in the equation for the small watershed scale.

Table 5. ANOVA of stepwise regression, including qualitative variables.

\begin{tabular}{|c|c|c|c|c|c|}
\hline Scale of research & Depth of soil layer & Source of variation & d.f. & $F$-ratio & Significance \\
\hline \multirow{12}{*}{$\begin{array}{l}\text { Small watershed } \\
\text { scale }\end{array}$} & \multirow{2}{*}{$0-20 \mathrm{~cm}$} & $\mathrm{~B}$ & 5 & 13.39 & $* *$ \\
\hline & & $\mathrm{X}_{5}$ & 1 & 7.87 & $* *$ \\
\hline & $20-40 \mathrm{~cm}$ & $\mathrm{~B}$ & 5 & 9.06 & $* *$ \\
\hline & \multirow{3}{*}{$40-60 \mathrm{~cm}$} & A & 4 & 3.89 & $*$ \\
\hline & & $\mathrm{B}$ & 5 & 4.25 & $* *$ \\
\hline & & $\mathrm{X}_{4}$ & 1 & 3.70 & ns \\
\hline & \multirow{2}{*}{$60-80 \mathrm{~cm}$} & $\mathrm{~A}$ & 4 & 5.46 & $* *$ \\
\hline & & $\mathrm{X}_{1}$ & 1 & 3.07 & $\mathrm{~ns}$ \\
\hline & $80-100 \mathrm{~cm}$ & $\mathrm{~A}$ & 4 & 17.75 & $* *$ \\
\hline & \multirow{3}{*}{ Depth-averaged } & $\mathrm{A}$ & 4 & 4.19 & $*$ \\
\hline & & $\mathrm{B}$ & 5 & 4.74 & $* *$ \\
\hline & & $X_{4}$ & 1 & 3.29 & $*$ \\
\hline \multirow{14}{*}{ Watershed scale } & $0-20 \mathrm{~cm}$ & $\mathrm{~B}$ & 5 & 8.72 & $* *$ \\
\hline & \multirow{3}{*}{$20-40 \mathrm{~cm}$} & $\mathrm{~B}$ & 5 & 9.11 & $* *$ \\
\hline & & $\mathrm{X}_{3}$ & 1 & 3.50 & $\mathrm{~ns}$ \\
\hline & & $\mathrm{X}_{5}$ & 1 & 5.57 & $*$ \\
\hline & \multirow[t]{2}{*}{$40-60 \mathrm{~cm}$} & $\mathrm{~B}$ & 5 & 6.49 & $* *$ \\
\hline & & $\mathrm{X}_{5}$ & 1 & 6.33 & $*$ \\
\hline & \multirow{3}{*}{$60-80 \mathrm{~cm}$} & $\mathrm{~B}$ & 5 & 3.94 & $* *$ \\
\hline & & $\mathrm{X}_{4}$ & 1 & 2.95 & $\mathrm{~ns}$ \\
\hline & & $X_{5}$ & 1 & 8.70 & $* *$ \\
\hline & \multirow{3}{*}{$80-100 \mathrm{~cm}$} & $\mathrm{X}_{1}$ & 1 & 4.11 & $*$ \\
\hline & & $\mathrm{X}_{4}$ & 1 & 5.33 & $*$ \\
\hline & & $\mathrm{X}_{5}$ & 1 & 8.95 & $* *$ \\
\hline & \multirow{2}{*}{ Depth-averaged } & $\mathrm{B}$ & 5 & 9.04 & $* *$ \\
\hline & & $\mathrm{X}_{5}$ & 1 & 9.02 & $* *$ \\
\hline
\end{tabular}

Notes: d.f. represents degrees of freedom; $F$-ratio $=\mathrm{MS}$ (treatment)/MS(error); * represents significance at the 0.05 level; $* *$ represents significance at the 0.01 level; ns represents not significant. A in the table represents the land use type. $\mathrm{B}$ represents different locations on the hill slope. $\mathrm{X}_{1}-\mathrm{X}_{5}$ represent relative elevation, cosine of the aspect, sine of the aspect (aspect), slope and vegetation cover, respectively. 
Table 6. Stepwise regression model of environmental factors and soil moisture.

\begin{tabular}{|c|c|c|c|}
\hline $\begin{array}{l}\text { Scale of } \\
\text { research }\end{array}$ & $\begin{array}{l}\text { Depth of } \\
\text { soil layer }\end{array}$ & Forecast model & $\begin{array}{c}\text { Regression } \\
\text { effect }\end{array}$ \\
\hline \multirow{6}{*}{$\begin{array}{l}\text { Small } \\
\text { watershed } \\
\text { scale }\end{array}$} & $0-20 \mathrm{~cm}$ & $y=0.114-0.04 \mathrm{~B}_{1}+0.014 \mathrm{~B}_{2}-0.034 \mathrm{~B}_{3}-0.023 \mathrm{~B}_{4}-0.039 \mathrm{~B}_{5}+0.0002 \mathrm{X}_{5}$ & $\mathrm{R}^{2}=0.72 * *$ \\
\hline & $20-40 \mathrm{~cm}$ & $y=0.147-0.041 \mathrm{~B}_{1}+0.01 \mathrm{~B}_{2}-0.028 \mathrm{~B}_{3}-0.025 \mathrm{~B}_{4}-0.035 \mathrm{~B}_{5}$ & $\mathrm{R}^{2}=0.62 * *$ \\
\hline & $40-60 \mathrm{~cm}$ & $\begin{array}{c}y=0.110+0.039 \mathrm{~A}_{1}+0.02 \mathrm{~A}_{2}+0.062 \mathrm{~A}_{3}+0.018 \mathrm{~A}_{4}-0.022 \mathrm{~B}_{1}+0.0006 \mathrm{~B}_{2}+0.001 \mathrm{~B}_{3}- \\
0.007 \mathrm{~B}_{4}-0.036 \mathrm{~B}_{5}+0.0008 \mathrm{X}_{4}\end{array}$ & $\mathrm{R}^{2}=0.74 * *$ \\
\hline & $60-80 \mathrm{~cm}$ & $y=0.136+0.010 \mathrm{~A}_{1}+0.011 \mathrm{~A}_{2}+0.062 \mathrm{~A}_{3}+0.024 \mathrm{~A}_{4}-0.0001 \mathrm{X}_{1}$ & $\mathrm{R}^{2}=0.66 * *$ \\
\hline & $80-100 \mathrm{~cm}$ & $y=0.083+0.032 \mathrm{~A}_{1}+0.030 \mathrm{~A}_{2}+0.109 \mathrm{~A}_{3}+0.049 \mathrm{~A}_{4}$ & $\mathrm{R}^{2}=0.71 * *$ \\
\hline & $\begin{array}{l}\text { Average on } \\
\text { all layers }\end{array}$ & $\begin{array}{c}y=0.108+0.022 \mathrm{~A}_{1}+0.013 \mathrm{~A}_{2}+0.057 \mathrm{~A}_{3}+0.016 \mathrm{~A}_{4}-0.020 \mathrm{~B}_{1}+0.007 \mathrm{~B}_{2}-0.004 \mathrm{~B}_{3}- \\
0.0150 \mathrm{~B}_{4}-0.028 \mathrm{~B}_{5}+0.0006 \mathrm{X}_{4}\end{array}$ & $\mathrm{R}^{2}=0.82 * *$ \\
\hline \multirow{6}{*}{$\begin{array}{l}\text { Watershed } \\
\text { scale }\end{array}$} & $0-20 \mathrm{~cm}$ & $y=0.118-0.029 \mathrm{~B}_{1}+0.013 \mathrm{~B}_{2}-0.031 \mathrm{~B}_{3}-0.012 \mathrm{~B}_{4}-0.024 \mathrm{~B}_{5}$ & $\mathrm{R}^{2}=0.38 * *$ \\
\hline & $20-40 \mathrm{~cm}$ & $y=0.145-0.027 \mathrm{~B}_{1}+0.004 \mathrm{~B}_{2}-0.034 \mathrm{~B}_{3}-0.012 \mathrm{~B}_{4}-0.022 \mathrm{~B}_{5}+0.005 \mathrm{X}_{3}-0.0001 \mathrm{X}_{5}$ & $\mathrm{R}^{2}=0.43 * *$ \\
\hline & $40-60 \mathrm{~cm}$ & $y=0.149-0.018 \mathrm{~B}_{1}+0.013 \mathrm{~B}_{2}-0.018 \mathrm{~B}_{3}+0.002 \mathrm{~B}_{4}-0.018 \mathrm{~B}_{5}-0.0001 \mathrm{X}_{5}$ & $\mathrm{R}^{2}=0.38 * *$ \\
\hline & $60-80 \mathrm{~cm}$ & $y=0.162-0.019 \mathrm{~B}_{1}+0.005 \mathrm{~B}_{2}-0.026 \mathrm{~B}_{3}-0.009 \mathrm{~B}_{4}-0.017 \mathrm{~B}_{5}-0.0004 \mathrm{X}_{4}-0.0002 \mathrm{X}_{5}$ & $\mathrm{R}^{2}=0.38 * *$ \\
\hline & $80-100 \mathrm{~cm}$ & $y=0.170-0.00007 \mathrm{X}_{1}-0.0005 \mathrm{X}_{4}-0.0002 \mathrm{X}_{5}$ & $\mathrm{R}^{2}=0.27 * *$ \\
\hline & $\begin{array}{l}\text { Average on } \\
\text { all layers }\end{array}$ & $y=0.144-0.022 \mathrm{~B}_{1}+0.009 \mathrm{~B}_{2}-0.020 \mathrm{~B}_{3}-0.007 \mathrm{~B}_{4}-0.019 \mathrm{~B}_{5}-0.0001 \mathrm{X}_{5}$ & $\mathrm{R}^{2}=0.45 * *$ \\
\hline
\end{tabular}

Notes: $\mathrm{A}$ in the table represents the land use type, where $\mathrm{A}_{1}-\mathrm{A}_{4}$ represent garden plot, woodland, cultivated land and wild grassland, respectively; $\mathrm{B}$ represents different locations on the hill slope, and $\mathrm{B}_{1}-\mathrm{B}_{5}$ represent the upper slope, lower slope, slope top, middle slope and middle-upper slope, respectively; $\mathrm{X}_{1}-\mathrm{X}_{5}$ represent relative elevation, cosine of the aspect, sine of the aspect (aspect), slope and vegetation cover, respectively; * represents significance at the 0.05 level; ** represents significance at the 0.01 level; ns represents not significant.

For the small watershed scale, we determined the order of significance for the influence of environmental factors on soil moisture values according to the number of times the environmental factors were introduced into the equation: location on the hill slope, land use type, slope, relative elevation and vegetation cover. The order of significance at the watershed scale was also determined: location on the hill slope, vegetation cover, slope, relative elevation and sine of the aspect. Obviously, the location on the hill slope was an important factor that influenced soil moisture values at both scales. Land use and vegetation cover were significant at the small watershed and watershed scales, respectively. Slope and relative elevation similarly influenced the soil moisture value at both scales. The order of significance of influencing factors on soil moisture values was different between the Muyu small watershed and the Ansai watershed, indicating that the influence of different environmental factors on soil moisture value variability was dependent on the scale.

The coefficient of determination, $\mathrm{R}^{2}$, reflects the proportion of the total variance in soil moisture values that can be explained by the model, and it can test the degree of similarity between the model prediction and the sampling data. The coefficient of determination, $\mathrm{R}^{2}$, was $0.618-0.744$ for the small watershed scale and $0.273-0.426$ for the watershed scale. These results indicate that as the scale increased, the explanatory power of the 14 selected environmental variables decreased, most likely due to changes in the movement and transfer processes of soil moisture values. There is a need for an adjustment or introduction of additional environmental factors into model forecasts in studies investigating the scale transformation of the spatial distribution of forest soil moisture values. 


\subsection{Scale Effects of the Spatial Distribution of Soil Moisture Values}

Scale effects on the spatial heterogeneity of soil moisture values are common, and the extent of variability in soil moisture value is positively correlated with the research scale [5]. Moreover, the characteristic parameters of soil moisture value variability, such as the variance coefficient, relevant distance and Moran I correlation index, all increase to different extents as the scale of the sampling increases within a certain range [23]. Famiglietti et al. [11] reported that the standard deviation of soil moisture values increased from 0.036 to 0.071 as the research scale increased from $2.5 \mathrm{~m}$ to $50 \mathrm{~km}$. Therefore, the spatial heterogeneity of soil moisture values depends on the scale, because the major factors and hydrological processes that control soil moisture value variability are different at different scales. Numerous studies have attempted to apply the research results from small scales to large scales to infer the corresponding large scale results based on temporally stable spatial point data. Rosnay et al. [13] used regression analyses with data that were measured multiple times at two scales to establish the corresponding scale transfer equations. This scale transformation approach can only be viewed as an empirical formula for statistics; it cannot reveal the environmental factors that affect the spatial distribution of soil moisture values and their variations at different scales. The present study discussed the scale effect of the spatial distribution in soil moisture values at two scales (small watershed and watershed) and revealed the change in the order of factors that influence these values as the scale increases. Additionally, as the scale increased, the forecasting ability of the environmental factors affecting soil moisture value decreased. Additional in-depth studies are needed to adjust or introduce additional environmental factors into soil moisture value forecasting methods at the watershed scale. These refinements will be an important basis for the study of soil moisture value scale transformation.

\section{Conclusions}

Soil moisture values were higher at sites that were closer to the main stream, and this influence decreased as the scale became larger. A smaller slope was more favorable for soil moisture value infiltration and transfer to deeper layers. Lush vegetation consumed soil moisture in the deeper layers. The correlation among slope, aspect, vegetation cover and soil moisture value increased with depth.

Soil moisture values at both scales were greatest on cultivated land, followed by wild grassland. The lowest values were found in the garden plot, woodland and shrubland. In the Ansai region, the low-density and low water consumption woodland or wild grassland should be preferred as the main land use type to maintain soil moisture and take full advantage of the ecological benefit of the "soil reservoir". The distribution of soil moisture values with respect to the location on the hill slope is ordered consecutively: upper slope $<$ middle-upper slope $<$ middle slope $<$ middle-lower slope $<$ lower slope. The deep layer soil moisture values of the slope top were high, being comparable to the soil moisture in the lower slope. Vegetation restoration on the Loess Plateau should account for the location on the hill slope, slope and elevation and should combine various land use types to form different spatial mosaic patterns. For example, low-density woodlands or wild grasslands would be appropriate in sites with low soil moisture content, such as upper slopes, high elevation areas and steep slopes.

The dominant factor controlling the spatial variability of soil moisture values varied at different scales. At the small watershed scale, the order of significance for the influence of environmental 
factors on soil moisture values was as follows: land use type, slope, relative elevation and vegetation cover. The order of significance at the watershed scale was also determined: location on the hill slope, vegetation cover, slope, relative elevation and sine of the aspect. This result indicated that the influence of different environmental factors on soil moisture value variability was dependent on the scale. Moreover, the explanatory power of environmental variables for soil moisture decreased as the scale increased. Therefore, relevant scale transformation work must be conducted with a complete understanding of the spatial variability of soil moisture values and the scale effect of its influencing factors.

Temporal variations are important for forecasting soil moisture content. Constructing regression models using dynamic soil moisture data to reveal the spatial variability of soil moisture values and the scale effect will be our future work.

\section{Practical Implications of the Study}

Our study revealed that soil moisture values of wild grassland are higher than that of woodland and shrubland, which indicates that wild grassland has a better capacity for water storage. The dominant tree species in the Ansai watershed woodlands is Robinia pseudoacacia, and the shrubland is dominated by Hippophae rhamnoides. The roots of Robinia pseudoacacia on the Loess Plateau can be as deep as 120 [32] or $190 \mathrm{~cm}$ [33]. The effective roots are predominantly concentrated between zeroand $60 \mathrm{~cm}$, especially in the range of 20-60 cm [32,34]. The roots of Hippophae rhamnoidesare mainly distributed within $0-100 \mathrm{~cm}$. Soil moisture value absorption and evaporative consumption in artificial woodland are much higher than in wild grassland, which causes significant moisture consumption in the corresponding soil layers. According to the regional vegetation on the Loess Plateau in Shanxi province, the vegetation distribution exhibits a zonal arrangement of "two lines across three regions": areas with annual average rainfall above $550 \mathrm{~mm}$ are deciduous, broad-leaved forests; areas with an annual average rainfall of 450-550 $\mathrm{mm}$ are forest-steppe zones and areas with an annual average rainfall below $450 \mathrm{~mm}$ are steppe [35]. The annual rainfall in Ansai is $505.3 \mathrm{~mm}$. Ansai is located in the forest-steppe zone and is unsuitable for planting high-density artificial woodland. Relevant research on a large-scale [36] indicates that local rainfall conditions determine whether forestation with Robinia pseudoacacia will improve, worsen or not have an effect on the local soil moisture value. Research also suggests that in an area with $509 \mathrm{~mm}$ rainfall, the growth of trees will cause water consumption, similar to the results of this study. In general, forestation in the Ansai watershed should adopt the low-density approach and select tree species with low water consumption or use wild grassland as the dominant land use type.

\section{Acknowledgments}

This work is supported by the Program for Yangtze Scholars and the Innovative Research Team at the University (No. IRT1108) and the National Natural Science Foundation of China (Nos. 41171069, 41001056, 41171156). The authors are grateful for the help from Ansai Research Station of Soil and Water Conservation, Chinese Academy of Sciences.

\section{Conflicts of Interest}

The authors declare no conflict of interest. 


\section{References}

1. Lin, H.S.; Kogelmann, W.; Walker, C.; Bruns, M.A. Soil moisture patterns in a forested catchment: A hydropedological perspective. Geoderma 2006, 131, 345-368.

2. Kim, S. Characterization of annual soil moisture response pattern on a hillslope in Bongsunsa Watershed, South Korea Sanghyun. J. Hydrol. 2012, 448-449, 100-111.

3. Qiu, Y.; Fu, B.J.; Wang, J.; Chen, L.D. Soil moisture variation in relation to topography and land use in a hillslope catchment of the Loess Plateau, China. J. Hydrol. 2001, 240, 243-263.

4. Lu, Y.Z.; Li, B.G.; Hu, K.L.; Xu, Y. Spatial variability of soil water under different landform in Erdos Plateau at beginning of summer [in Chinese]. J. China Agric. Univ. 2002, 7, 38-43.

5. Western, A.W.; Blöschl, G. On the spatial scaling of soil moisture. J. Hydrol. 1999, 217, 203-224.

6. Baroni, G.; Ortuani, B.; Facchi, A.; Gandolfi, C. The role of vegetation and soil properties on the spatio-temporal variability of the surface soil moisture in a maize-cropped field. J. Hydrol. 2013, $489,148-159$.

7. Jawson, S.D.; Niemann, J.D. Spatial patterns from EOF analysis of soil moisture at a large scale and their dependence on soil, land-use, and topographic properties. Adv. Water Resour. 2007, 30, 366-381.

8. Fu, B.J.; Wang, J.; Chen, L.D.; Qiu, Y. The effects of land use on soil moisture variation in the Danangou catchment of the Loess Plateau, China. Catena 2003, 54, 197-213.

9. Venkatesh, B.; Lakshman, N.; Purandara, B.K.; Reddy, V.B. Analysis of observed soil moisture patterns under different land coversin Western Ghats, India. J. Hydrol. 2011, 397, 281-294.

10. Mark, A.P.; Niemann, J.D. Analysis and estimation of soil moisture at the catchment scale using EOFs. J. Hydrol. 2007, 334, 388-404.

11. Famiglietti, J.S.; Ryu, D.; Berg, A.A.; Rodell, M.; Jackson, T.J. Field observations of soil moisture variability across scales. Water. Resour. Res. 2008, 44, doi:10.1029/2006WR005804.

12. Zhu, Q.; Lin, H.S. Influences of soil, terrain, and crop growth on soil moisture variation from transect to farm scales. Geoderma 2011, 163, 45-54.

13. Rosnay, P.D.; Gruhier, C.; Timouk, F.; Baup, F.; Mougin, E.; Hiernaux, P.; Kergoat, L.; LeDantec, V. Multi-scale soil moisture measurements at the Gourma meso-scale site in Mali. J. Hydrol. 2009. 375, 241-252.

14. Miralles, D.G.; Crow, W.T.; Cosh, M.H. Estimating spatial sampling errors in coarse-scale soil moisture estimates derived from point-scale observations. J. Hydrometeorol. 2010, 11, 1423-1429.

15. Brocca, L.; Tullo, T.; Melone, F.; Moramarco, T.; Morbidelli, R. Catchment scale soil moisture spatial-temporal variability. J. Hydrol. 2012, 422-423, 63-75.

16. Heathman, G.C.; Cosh, M.H.; Merwade , V.; Han, E. Multi-scale temporal stability analysis of surface and subsurface soil moisture within the Upper Cedar Creek Watershed, Indiana. Catena 2012, 95, 91-103.

17. Liu, C.L.; Shao, M.A. Soil hydraulic properties and their influences on soil water content under different land uses in Liudaogou watershed of Loess Plateau [in Chinese]. Chin. J. Appl. Ecol. 2008, 19, 2400-2407.

18. Liu, M.; Jiang, D.S.; Huang, G.J.; Fan, X.K.; Chang, C.E. An analysis to the differences of soil water in varied places of hillslopes [in Chinese]. Bull. Soil Water Conserv. 1990, 10, 16-20. 
19. Hu, W.; Shao, M.A.; Wang, Q.J. Study on spatial variability of soil moisture on the recultivated slope-land on the Loess Plateau [in Chinese]. Adv. Water Sci. 2006, 17, 74-81.

20. Yao, X.L.; Fu, B.J.; Lü, Y.H. Spatial patterns of soil moisture at transect scale in the Loess Plateau of China [in Chinese]. Acta Ecol. Sin. 2012, 32, 4961-4968.

21. Qiu, Y.; Fu, B.J.; Wang, J. Spatial heterogeneity of soil moisture content on the Loess Plateau, China and its relation to influencing factors [in Chinese]. Chin. J. Appl. Ecol. 2001, 12, 715-720.

22. Huang, Y.L.; Chen, L.D.; Fu, B.J.; Wang, Y.L. Spatial pattern of soil water and its influencing factors in a gully catchment of the Loess Plateau [in Chinese]. J. Nat. Resour. 2005, 20, 483-492.

23. Hu, W.; Shao, M.A.; Wang, Q.J. Scale-dependency of spatial variability of soil moisture on a degraded slope-land on the Loess Plateau [in Chinese]. Trans. Chin. Soc. Agric. Eng. 2005, 21, 11-16.

24. Liu, J.L.; Ma, X.Y.; Zhang, Z.H. Multifractal study on spatial variability of soil water and salt and its scale effect [in Chinese]. Trans. Chin. Soc. Agric. Eng. 2010, 26, 81-86.

25. Li, Y.S.; Han, S.F.; Wang, Z.H. Soil water properties and its zonation in the Loess Plateau [in Chinese]. Res. Soil Water Conserv. 1985, 2, 2-17.

26. Grayson, R.B.; Blöschl, G.; Western, A.W.; McMahon, T.A. Advances in the use of observed spatial patterns of catchment hydrological response. Adv. Water Resour. 2002, 25, 1313-1334.

27. Famiglietti, J.S.; Rudnicki, J.W.; Rodell, M. Variability in surface moisture content along a hillslope transect: Rattlesnake Hill, Texas. J. Hydrol. 1998, 210, 259-281.

28. Wang, S.; Fu, B.J.; Gao, G.Y.; Yao, X.L.; Zhou, J. Soil moisture and evapotranspiration of different land cover types in the Loess Plateau, China. Hydrol. Earth Syst. Sci. 2012, 16, 2883-2892.

29. Wang, G.L.; Liu, G.B.; Dang, X.H. Effects of land use on soil moisture in loess hilly and gully region of China [in Chinese]. Trans. Chin. Soc. Agric. Eng. 2009, 25, 31-35.

30. Penna, D.; Borga, M.; Norbiato, D.; Fontana, G.D. Hillslope scale soil moisture variability in a steep alpine terrain. J. Hydrol. 2009, 364, 311-327.

31. He, F.H.; Huang, M.B.; Dang, T.H. Soil water distribution characteristics in Wangdonggou watershed in gully region of Loess Plateau [in Chinese]. Bull. Soil Water Conserv. 2002, 22, 7-9.

32. Liu, X.P.; Chen, L.H.; Chen, J.H. Study on the distribution of root density of Robinia pseudoacacia L. and Pinus tabulae form is Carr [in Chinese]. Arid Zone Res. 2007, 24, 647-651.

33. Wang, J.X.; Wang, D.H.; Liu, G.Q. Distribution characteristics of effective root density in the planted Robinia Pseudoacacia and Platycladus Orientalis forest site [in Chinese]. Acta Bot. Boreal. Occident. Sin. 2004, 24, 2208-2214.

34. Cao, Y.; Zhao, Z.; Qu, M.; Cheng, X.R.; Wang, D.H. Effects of Robinia Pseudoacacia roots on deep soil moisture status [in Chinese]. Chin. J. Appl. Ecol. 2006, 17, 765-768.

35. Zou, H.Y. A study on correlation between vegetation division and construction of forest and grasslands in Loess Plateau of northern Shannxi [in Chinese]. Res. Soil Water Conserv. 2000, 7 , 96-101.

36. Jin, T.T.; Fu, B.J.; Liu, G.H.; Wang, Z. Hydrologic feasibility of artificial forestation in the semi-arid Loess Plateau of China. Hydrol. Earth Syst. Sci. 2011, 15, 2519-2530.

(C) 2013 by the authors; licensee MDPI, Basel, Switzerland. This article is an open access article distributed under the terms and conditions of the Creative Commons Attribution license (http://creativecommons.org/licenses/by/3.0/). 